\title{
FISH comets show that the salvage enzymeTK1 contributes to gene-specific DNA repair
}

\author{
Katherine A. McAllister ${ }^{1}$, Akeel A. Yasseen ${ }^{2}$, George McKerr ${ }^{1}$, C. S. Downes ${ }^{1}{ }^{*}$ and \\ Valerie J. McKelvey-Martin'
}

1 School of Biomedical Sciences, University of Ulster, Coleraine, UK

${ }^{2}$ Department of Pathology and Forensic Medicine, Faculty of Medicine, University of Kufa, Kufa, Iraq

\section{Edited by:}

Andrew Collins, University of Oslo, Norway

\section{Reviewed by:}

Meredith Emily Kennedy Calvert, Temasek Lifesciences Laboratory, Singapore

Alex Michael Ward, Duke-NUS

Graduate Medical School, Singapore

\section{*Correspondence:}

C. S. Downes, School of Biomedical Sciences, University of Ulster,

Coleraine, BT52 1SA, UK

e-mail:cs.downes@ulster.ac.uk
Thymidine kinase 1 (TK1) is a salvage enzyme that phosphorylates thymidine, imported from surrounding fluids, to create ATMP, which is further phosphorylated to the DNA precursor dTTP. TK1 deficiency has for a long time been known to cause increased cellular sensitivity to DNA damage. We have examined preferential strand break repair of DNA domains in $\mathrm{TK}^{+}{ }^{+}$and TK1 ${ }^{-}$clones of the Raji cell line, by the Comet-FISH technique, in bulk DNA and in the actively transcribed tumor suppressor (TP53) and human telomerase reverse transcriptase (hTERT) gene regions, over $1 \mathrm{~h}$ after $5 \mathrm{~Gy} \gamma$-irradiation. Results showed that repair of the TP53 and hTERT gene regions was more efficient in $\mathrm{TK} 1^{+}$compared to $\mathrm{TK} 1^{-}$cells, a trend also reflected to a lesser degree in genomic DNA repair between the cell-lines. The targeted gene-specific repair in $\mathrm{TK}^{+}$cells occurred rapidly, mainly over the first 15 min repair-period. Therefore, TK1 is needed for preferential repair of actively transcribed regions, through a previously unsuspected mechanism. In principle, TK1 could exert its protective effects through supply of a supplementary dTTP pool for accurate repair of damaged genes; but Raji $\mathrm{TK} 1^{+}$cells in thymidine free media still show preferential repair of transcribed regions. TK1 therefore does not exert its protective effects through dTTP pools, but through another unidentified mechanism, which affects sensitivity to and mutagenicity by DNA damaging agents.

Keywords: FISH comet, gene-specific repair, radiation damage, thymidine kinase

\section{INTRODUCTION}

Human thymidine kinase 1 (TK1) is a salvage enzyme that phosphorylates thymidine to create dTMP, which is later converted by thymidylate kinase and nucleoside diphosphate kinase to dTTP, a precursor for DNA metabolism (Segura-Pena et al., 2007). This is usually the minor pathway for dTTP synthesis, subsidiary to the de novo pathway in which ribonucleotide reductase converts UDP to dUDP, which is dephosphorylated to dUMP and then methylated by thymidylate synthase to dTMP. TK1 is not essential for viability (Dobrovolsky et al., 2003). A related enzyme, TK2, is mitochondrial and irrelevant to nuclear events.

While the functions of TK1 are clearly related to the processes of DNA replication and cell proliferation, many studies in the literature demonstrate a protective role for the protein during cellular responses to DNA damage. Human and rodent in vitro studies show that deficiency of the protein causes increased sensitivity to a diverse range of DNA damaging agents, including ionizing radiation (McKenna and Hickey, 1981; McKenna and Yasseen, 1982; McKenna et al., 1988; al-Nabulsi et al., 1994; Best et al., 1994; Wakazono et al., 1996). In this context, it is noticeable that TK1 mRNA is induced not only in S phase and G2 but also following ionizing radiation, causing a concomitant increase of enzymatic activity (Boothman et al., 1994; Wei et al., 1999; Castro Kreder et al., 2002; Haveman et al., 2006). More recently, it has been shown that TK1 is upregulated in different tumor types in response to DNA damage, and that the cellular response to genotoxins causes nuclear localization of TK1; an interesting finding given that the salvage enzyme has previously been regarded as solely cytoplasmic (Chen et al., 2010). These studies suggest that TK1 may somehow affect DNA metabolism in a way not obviously explained by its salvage role.

The protective effect of TK1 might be due to its maintaining of the efficiency of DNA repair during recovery from genotoxic insults. TK1 deficiency not only restricts the dTTP pool but upsets the balance of all four dNTP precursors (Wilkinson and McKenna, 1989). Deficiency of the TK1 regulated dTTP pool causes decreased viability and increased mutation after treatment with mutagenic agents (Wakazono et al., 1996; Kubota et al., 1998; Hyland et al., 2000). Analagously, a reduction in dTTP pools by silencing of thymidylate kinase also sensitizes cells to DNA damage (Hu and Chang, 2008). Recent work in colon carcinoma cells (Chen et al., 2010) showed that knockdown of TK1 decreases the efficiency of double-strand DNA break repair during recovery from DNA damage. Chen etal. (2010) also found that the TP53 status of the tumor cells affected the level of TK1 after DNA damage.

We address in this study TK1's effect on the kinetics of repair after DNA damage, in particular the repair of DNA damage occurring in specific areas of the genome. Many studies have documented that repair occurs at a more accelerated rate in transcribed 
gene regions such as TP53, compared to that of total DNA (reviewed by Sarasin and Stary, 2007). Such transcription-coupled repair has the capacity to reduce mutations in vital domains of the genome. While earlier DNA repair studies using murine cells have shown that TK1 deficiency does not prevent bulk excision repair from occurring after genotoxic insult (McKenna and McKelvey, 1986), there has been no evidence for its effect on the faster repair that occurs with damage to specific gene regions. The Comet assay is an ideal method for investigations of the kinetics of repair of damage induced in nuclear DNA by ionizing radiation. The strand breaks induced are typically rejoined quickly, most breaks disappearing within $30 \mathrm{~min}$ (reviewed by Frankenberg-Schwager, 1989). The method when combined with the use of fluorescent hybridization probes (Comet-FISH) allows the study of repair kinetics in gene-regions of interest by quantifying the rate of strand break repair within such target genes (Santos et al., 1997; McKelveyMartin et al., 1998; McKenna et al., 2003; Horvathova et al., 2004; Glei et al., 2007).

This investigation was carried out to determine whether TK1 may affect the damage response in two selected transcribed gene regions [TP53 and human telomerase reverse transcriptase (hTERT)] both of which are actively transcribed by Raji $\mathrm{TK}^{+}$and $\mathrm{TK}^{-}{ }^{-}$clones, and thereby to provide further insight into potential mechanisms of mutagenesis and carcinogenesis induced by misrepair of DNA. Human TP53 is a well-characterized tumor suppressor gene and is located on the short arm of chromosome 17 (17p13.1; Matlashewski et al., 1984). TP53 is induced by $\gamma$-irradiation (McKay etal., 1999) and is in a domain seen to be rapidly repaired after $\gamma$-irradiation in comparison to other genes (McKenna et al., 2003, 2012). The hTERT gene (5q15.33), which codes for hTERT, the catalytic subunit of the telomerase enzyme, is upregulated in the majority of cancer cells (Hiyama and Hiyama, 2003); strand break repair of $\gamma$-irradiation damage to the hTERT gene domain is likewise rapid (McKenna et al., 2012).

The position of FISH signals within the Comet head or tail indicates whether or not damage has occurred, or not yet been repaired, to the gene-region selected by the probe; this can be compared to damage in global DNA. In this study we applied the Comet-FISH protocol to study DNA repair in $\mathrm{TK}^{+}$and $\mathrm{TK} 1^{-}$ clones of the human lymphoblastoid cell line Raji. The possibility that TK1 exerts its protective effects through the dTTP pool was also investigated by growing Raji $\mathrm{TK} 1^{+}$cells in thymidine free media. Repair was followed over a 1-h period following exposure to $5 \mathrm{~Gy} \gamma$-irradiation.

\section{MATERIALS AND METHODS CELL-LINES AND CELL CULTURE}

$\mathrm{TK}^{-}$and $\mathrm{TK}^{+}{ }^{+}$clones of the Raji lymphoblastoid cell line were grown in RPMI 1640 culture media, supplemented with $15 \%$ fetal bovine serum (FBS), $2 \mathrm{mM}$ glutamine, and antibiotics $(100 \mathrm{U} / \mathrm{ml}$ penicillin, $0.1 \mathrm{mg} / \mathrm{ml}$ streptomycin). Raji cell-lines were purchased from the European Collection of Cell Cultures (ECACC, Salisbury, UK). In thymidine free experiments, $\mathrm{TK}^{+}{ }^{+}$cells were first washed in PBS, then cultured in thymidine free media containing dialyzed FBS to remove the salvage dTTP pool. The Werner syndrome (WS) cell line was obtained from the Coriell Cell
Repository (Camden, NJ, USA) and maintained in minimum essential medium, supplemented with 15\% FBS and glutamine, penicillin, and streptomycin as above. The GM38 normal human fibroblast cell-line was obtained from the Human Genetic Msitory (Camden, NJ, USA) and cultured in Eagle's minimum essential medium supplemented with $20 \%$ FBS, 4\% essential amino acids, $2 \%$ non-essential and glutamine, penicillin, and streptomycin as above. The GM38 cell line actively expresses TP53 (Glei et al., 2007) and served both as a positive and negative PCR control to study TP53 and hTERT gene expression, respectively. The WS cell line is immortalized with the hTERT gene and therefore served as a PCR positive control to examine hTERT gene expression in Raji cells.

\section{CHARACTERIZATION OF RAJI CELLS}

Raji TK1 ${ }^{-}$cells were cultured in $5 \mu \mathrm{g} / \mathrm{ml}$ trifluorothymidine (TFT; Sigma, Poole, UK), which is lethal to $\mathrm{TK}^{+}{ }^{+}$cells, to confirm the cellular phenotype. TK assays were used to determine the activity of TK1 in Raji cells (McKenna etal., 1985). Metaphase spreads ( $n=100$ ) were examined to quantify chromosome numbers in Raji cells for general characterization and to correlate with later FISH spot numbers (McKenna et al., 2003).

\section{hTERT AND TP53 GENE EXPRESSION}

Total RNA was extracted from each of the four cell lines using an RNeasy Mini kit (Qiagen, Mississauga, MD, USA); integrity was verified by $1 \%$ gel electrophoresis and quantity and quality determined using a NanoDrop ND-1000 UV-VIS Spectrophotometer (Wilmington, DE, USA). Complementary DNA was generated using a Superscript II RNase H-Reverse Transcriptase Kit (Invitrogen, Renfrew, UK) according to the manufacturer's protocol. $\beta$-actin served as the internal control in RTPCR reactions. Template cDNA was amplified for PCR using GoTaq DNA Polymerase (Promega, Southampthon, UK) in the presence of primers specific for the $\beta$-actin gene: 5'AGAAAATCTGGCACCACACC-3' (sense) and $5^{\prime}$ CCATCTCTTGCTCGAAGTCC-3' (anti-sense), or primers specific for the hTERT gene: 5'CTCACCTTCAACCGCGG-3' (sense) and 5'TTGCTGAAATGGGAGCT-3' (anti-sense). Reaction conditions for $\beta$-actin were 40 cycles of denaturation at $96^{\circ} \mathrm{C}$ for $1 \mathrm{~min}$, annealing at $55^{\circ} \mathrm{C}$ for $30 \mathrm{~s}$ and extension at $72^{\circ} \mathrm{C}$ for $10 \mathrm{~min}$; conditions for hTERT were 35 cycles of denaturation at $94^{\circ} \mathrm{C}$ for $45 \mathrm{~s}$, annealing at $60^{\circ} \mathrm{C}$ for $45 \mathrm{~s}$, and extension at $72^{\circ} \mathrm{C}$ for $90 \mathrm{~s}$. Platinum TAQ DNA polymerase (Invitrogen, Renfrew, UK) was used to amplify the TP53 gene using the following primers: $5^{\prime}$-TCACTGCCATGGAGGAG-3' (sense) and $5^{\prime}$-TCAGTGGGGAACAAGAAG-3' (anti-sense). PCR reactions conditions were: 35 cycles of denaturation at $94^{\circ} \mathrm{C}$ for $1 \mathrm{~min}$, annealing at $50^{\circ} \mathrm{C}$ for $30 \mathrm{~s}$, and extension at $72^{\circ} \mathrm{C}$ for $2 \mathrm{~min}$. A final elongation step of $10 \mathrm{~min}$ was used to ensure that any remaining single stranded DNA was completely copied.

\section{COMET-FISH ASSAY}

For the alkaline Comet assay, cells were embedded in agarose onto Dakin fully frosted microscopic slides (Labcraft, London, UK), and subjected to a dose of $5 \mathrm{~Gy}$ irradiation using a Cs ${ }^{137}$ source. Following irradiation slides were quickly immersed in repair medium 
at $37^{\circ} \mathrm{C}$ for either 15,30 , or $60 \mathrm{~min}$, then drained and placed in alkaline lysis solution (2.5 M NaCl, $100 \mathrm{mM} \mathrm{Na} 2$ EDTA, $10 \mathrm{mM}$ Tris, $\mathrm{pH} 10$, and $1 \%$ Triton $\mathrm{X}-100$ added before use) for $1 \mathrm{~h}$ at $4^{\circ} \mathrm{C}$. DNA was left to unwind in electrophoresis buffer $(300 \mathrm{mM}$ $\mathrm{NaOH}, 1 \mathrm{mM} \mathrm{Na} 2 \mathrm{EDTA}$, pH13) for $20 \mathrm{~min}$. Electrophoresis was conducted for $20 \mathrm{~min}$ at $25 \mathrm{~V}$ and $300 \mathrm{~mA}$, after which slides were washed with three changes of neutralization buffer $(0.4 \mathrm{M}$ Tris, $\mathrm{pH} 7.5)$.

Target DNA was prepared for FISH by a 5 min wash with 2X SSC (3 $\mathrm{M}$ sodium citrate, $\mathrm{pH}$ 5.3), and subsequent dehydration with increasing concentrations of ethanol $(70,85,100 \%)$. Multicolor Comet-FISH was performed using a fragmented locus-specific identifier (LSI) Spectrum-Orange-labeled TP53 DNA probe spanning a $140 \mathrm{~kb}$ region containing the $20 \mathrm{~kb}$ TP53 gene (Vysis, Surrey, UK), in conjunction with a LSI direct labeled Spectrum Green hTERT probe, spanning a $180 \mathrm{~kb}$ region containing the $40 \mathrm{~kb}$ hTERT gene (Q-Biogene, Cambridge, UK). Equal concentrations of a TP53 and hTERT probe mix were applied to each slide. Co-denaturation of DNA was performed at $80^{\circ} \mathrm{C}$ ( $2 \mathrm{~min}$ ) followed by a 16 -h hybridization period at $37^{\circ} \mathrm{C}$ in a dark, humidified chamber. Following hybridization, excess probe was removed at $45^{\circ} \mathrm{C}$ using three $10 \mathrm{~min}$ washes of $50 \%$ formamide and $2 \mathrm{X}$ SSC, a $10 \mathrm{~m}$ wash with $2 \mathrm{X}$ SSC and a final $5 \mathrm{~min} 2 \mathrm{X}$ SSC and $0.1 \%$ Igepal wash. Slides were left to air dry for $1 \mathrm{~h}$ then counterstained with $16 \mu \mathrm{l} 4^{\prime}$ 6-diamidino-22phenylindole (DAPI) for immediate observation. All reagents for the Comet-FISH assay were purchased from Sigma, Poole, UK unless otherwise stated.

\section{COMET FISH MICROSCOPY AND ANALYSIS}

The slides were viewed using an epifluorescence microscope (Nikon Eclipse E400) using a triple bandpass filter (Chroma HiQ) that enabled the simultaneous detection of DAPI (overall genome) and both spectrum orange (TP53 gene region) and spectrum green (hTERT gene region) for the enumeration of FISH signals. Standard Comet parameter measurements, including \% comet tail DNA, were recorded using the Komet 5.0 digital imaging system (Kinetic Imaging Ltd., Liverpool, UK).

Studies of repair of bulk DNA selected the measurement \% comet tail DNA, as the amount of DNA in the tail (relative to the comet head) is proportional to the number of $\gamma$-irradiation induced strand breaks. For DNA damage and repair to the p53 and hTERT gene regions the numbers of fluorescent probes detected in the comet head and tail were quantified over timed intervals during a $1-\mathrm{h}$ incubation period. The repositioning of the gene-specific signals from the comet tail into the head over the incubation period provides evidence for repair of lesions occurring within and around the TP53 and/or hTERT gene locus. The level of DNA repair in the TP53 and hTERT gene region was examined using the parameter \% TP53/hTERT signals in the comet tail.

\section{STATISTICAL ANALYSIS}

One slide was analyzed from each dose point, and per slide 50 comets were scored. Three independent experiments were conducted to generate each data point ( 150 cells scored in total per cell line). The normality distribution of the entire comet-FISH dataset was visually inspected from normal probability plots and evaluated using the Shapiro-Wilk $W$-test. The Mann-Whitney test was applied to evaluate comparisons between the non-parametric comet-FISH dataset for the $\mathrm{TK}^{+}{ }^{+}$and $\mathrm{TK} 1^{-}$clones. A difference with a $p<0.05$ was deemed significant. Results were analyzed using GraphPad Prism version 5 (UK).

\section{RESULTS}

\section{CHARACTERIZATION OF RAJI CELLS}

The Raji cells used are from lines that were originally created in the 1990s: we have therefore checked that they have retained their original phenotypes. The $\mathrm{TK} 1^{+}$line retain sensitivity to the toxic thymidine analog trifluorothymidine (Karran et al., 1990), while $\mathrm{TK}^{-}{ }^{-}$cells which cannot metabolize it remain resistant. Correspondingly, incorporation of tritiated thymidine is linear in $\mathrm{TK}^{+}$ cells, negligible in $\mathrm{TK}^{-}$(Figure 1). The TK1 ${ }^{-}$nature of the Raji clones, first established several years ago (Hampar et al., 1971), has therefore been maintained.

Metaphase spread analysis revealed that Raji TK1 ${ }^{+}$and $\mathrm{TK}^{-}$ cells have a near diploid mainline featuring a population of cells ranging from 42-50 chromosomes. The modal chromosome number for $\mathrm{TK}^{-}{ }^{-}$was 46 while for $\mathrm{TK}^{+}{ }^{+}$it was 47 . A small, more aneuploid population in both cell-lines increased the overall mean number of chromosomes to 54 and 52 for $\mathrm{TK}^{-}$and $\mathrm{TK}^{+}$ respectively.

We have used TP53 and hTERT as markers for transcribed gene repair: it was therefore necessary to check they are in fact transcribed in both cell lines. They are, as shown in (Figure 2). A sample was considered positive for the hTERT gene expression by the presence of a 200 base pair amplicon (Figure 2C), as was the case for every cell-line except the fibroblast cell-line GM38. TP53 gene expression was also detected in both Raji clones and the normal fibroblast, GM38, as shown in Figure 2D by the presence of a 1220-base pair amplicon. Sequencing data of the TP53 gene in the Raji cell-lines also confirmed that the alleles were identical in both, and therefore any difference in DNA repair could not be accounted for by mutations in this key DNA repair gene (sequencing data not shown, supplementary).

\section{DNA REPAIR IN TK1 + AND TK1 - CELLS}

Comet-FISH experiments were evaluated by quantifying the number of TP53 and hTERT hybridization spots located in the comet head or tail of $\mathrm{TK}^{+}$and $\mathrm{TK}^{-}$at each repair incubation time as shown both in representative images in Figure 3 and the data in Table 1. FISH comet tail spots were almost entirely absent in both un-irradiated controls; and on account of the aneuploidy and the post-replicative elements in the population, the average spot number in the comet head was above two (Figure 3A). Post-irradiation, both cell-lines showed an increase in TP53 and hTERT probe signal in the comet tail, which is indicative of damage to both gene regions (Figures $3 \mathbf{B}, \mathbf{C}$ ). A notable finding in Raji $\mathrm{TK}^{+}{ }^{+}$cells (Table 1 ) was a rapid rate of gene-specific repair that featured significant decreases in the number of TP53 and hTERT tail spots at 15 min compared to $\mathrm{TK}^{-}(p<0.0001)$ and also at 30-60 min $(p<0.0001)$. Repair continued at a slower rate for the remainder of the repair period in $\mathrm{TK}^{+}$cells so that by $60 \mathrm{~min}$ there was no signal left of either probe in 

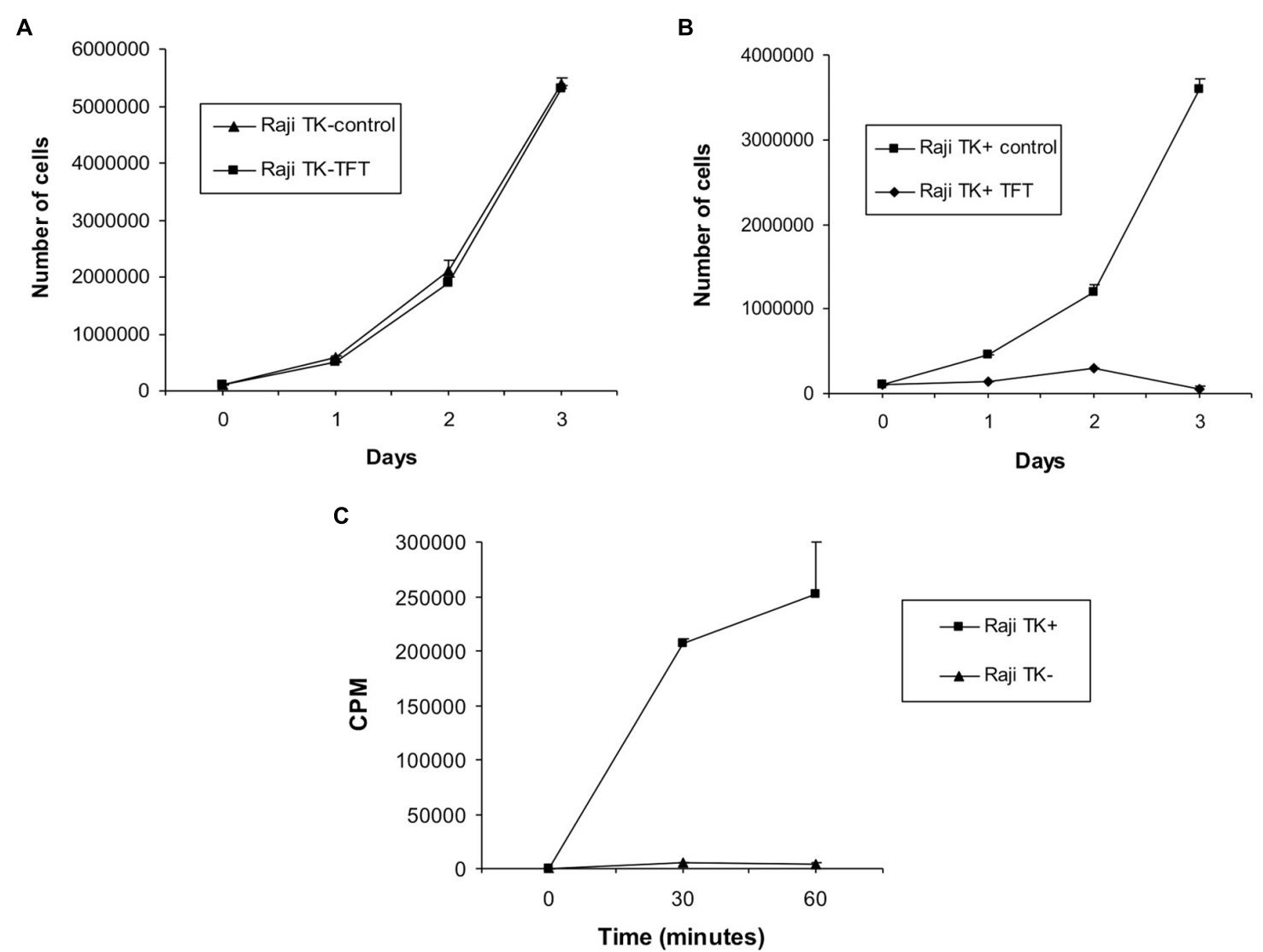

FIGURE 1 | Confirmation of cellular phenotype in Raji cells. (A) Effect of culturing TK1 ${ }^{-}$cells and (B) TK1 ${ }^{+}$cells in $5 \mu \mathrm{g} / \mathrm{ml}$ TFT compared to untreated control cells. Culture of Raji cells in TFT proved toxic to the $\mathrm{TK} 1^{+}$clones whereas $\mathrm{TK} 1^{-}$cells were resistant. Only cells containing functional TK1 can incorporate TFT and uptake of the chemical results in cell death. Therefore Raji TK1- cells lack TK1 functional protein. (C) Tritium counts obtained from Raji TK $1^{+}$and TK $1^{-}$clones during the TK assay expressed in counts per minute (CPM). The graph shows that the incorporation of ${ }^{3} \mathrm{H}$-thymidine is greatly reduced in Raji TK1 ${ }^{-}$cells compared to $\mathrm{TK}^{+}{ }^{+}$. The ability of cells to incorporate ${ }^{3} \mathrm{H}$-thymidine into nucleic acids is an approximate measure of cellular thymidine kinase activity; therefore Raji TK1 ${ }^{-}$cells lack functional TK1 protein. The results in each graph data-point represent the mean \pm SEM of three independent experiments. the tail (Figure 3D). In comparison, gene-specific repair was found to be stalled in $\mathrm{TK}^{-}$cells and the comet-tail FISH signals for each gene probe began to diminish only after $15 \mathrm{~min}$ (Figure 3E).

The level of strand break repair in the specific gene-regions was compared between $\mathrm{TK}^{+}{ }^{+}$and $\mathrm{TK} 1^{-}$cells using the parameter “\% TP53/hTERT signals in the comet tail” (Figures 4A,B). There was found to be a significant reduction $(p<0.0001)$ in the $\%$ of TP53 and hTERT tail signals at each time-point in Raji TK1 ${ }^{+}$ cells compared to $\mathrm{TK}^{-}$(Figures $4 \mathrm{~A}, \mathrm{~B}$ ). The most prominent occurred at $15 \mathrm{~min}$, with a difference between the Raji clones of $35.18 \pm 3.56$ for TP53 tail spots and $29.82 \pm 4.34$ for hTERT tail spots. The delayed reduction of \% FISH signals in the comet tail for each gene over the hourly incubation period demonstrates that $\mathrm{TK}^{-}{ }^{-}$are severely compromised in gene region repair kinetics compared to $\mathrm{TK}^{+}$.

This may be compared to the levels of radiation-induced strand breaks in bulk genomic DNA, which were reduced over the $1-\mathrm{h}$ repair period in a similar pattern for both Raji $\mathrm{TK}^{+}$ and $\mathrm{TK}^{-}$cells. The percentage of total DNA in the Comet tail ranged from 32 to $8 \%$ in $\mathrm{TK}^{+}$cells and from 31 to $10.11 \%$ in $\mathrm{TK}^{-}$cells (Figures 4C,D). Statistics showed that $\mathrm{TK}^{+}$cells had significantly but slightly greater levels of bulk DNA repair at both 15 and 30 repair minutes $(p>0.05)$ compared to $\mathrm{TK}^{-}$ cells.

The level of strand break repair in the specific gene-regions was compared between $\mathrm{TK}^{+}{ }^{+}$and $\mathrm{TK} 1^{-}$cells using the parameter "\% TP53/hTERT signals in the comet tail" (Figures 4A,B). There was found to be a significant reduction $(p<0.0001)$ in the \% of TP53 and hTERT tail signals at each time-point in Raji $\mathrm{TK}^{+}$cells compared to $\mathrm{TK} 1^{-}$(Figures 4A,B). The most prominent reduction occurred at $15 \mathrm{~min}$, with a difference between the Raji clones of $35.18 \pm 3.56$ for TP53 tail spots and $29.82 \pm 4.34$ for hTERT tail spots. The delayed reduction of \% FISH signals in the comet tail for each gene over the hourly incubation period demonstrates that $\mathrm{TK}^{-}$are severely compromised in gene region repair kinetics compared to $\mathrm{TK}^{+}$.

Figure 4C evaluates the mean \% comet tail damage in Raji $\mathrm{TK} 1^{+}$cells and shows an accelerated reduction of tail TP53 and 
A

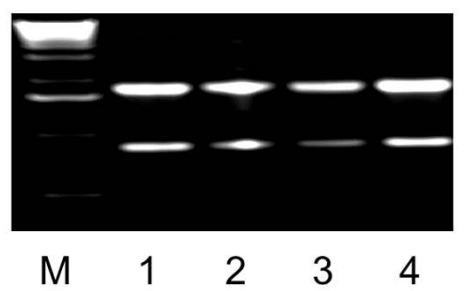

B

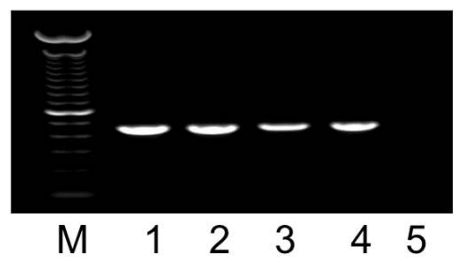

C

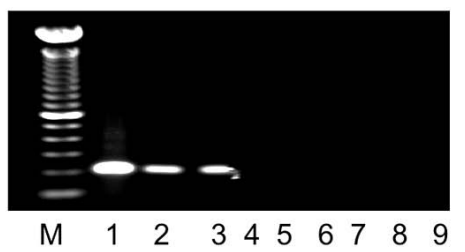

D

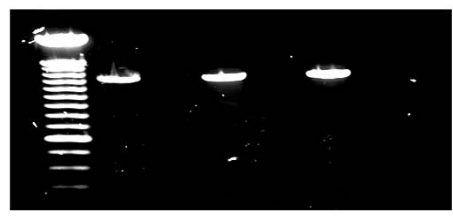

$\begin{array}{lllllll}M 1 & 2 & 3 & 4 & 5 & 6 & 7\end{array}$
RNA EXTRACTIONS

1. Werner syndrome

2. Raji $\mathrm{TK}^{+}$

3. Raji TK-

4. GM38

\section{B-ACTIN GENE EXPRESSIOI \\ 1. Werner syndrome RTPCR \\ 2. Raji TK ${ }^{+}$RTPCR \\ 3. Raji TK- RTPCR \\ 4. GM38 RTPCR \\ 5. PCR water control}

\section{HTERT GENE EXPRESSION \\ 1. Werner syndrome RTPCR \\ 2. Raji TK ${ }^{+}$RTPCR \\ 3. Raji TK-RTPCR \\ 4. GM38 RTPCR \\ 5-8 RTPCR- controls \\ 9. PCR water control}

FIGURE 2 | Investigation of TP53 and hTERT status in Raji cells using RTPCR. (A) RNA extraction. Lane 1 Werner Syndrome (WS), lane 2 TK1 ${ }^{+}$, lane 3 TK1 ${ }^{-}$, lane $4 \mathrm{GM} 38, \mathrm{M}$ is a $1 \mathrm{~kb}$ ladder. (B) $\beta$-actin gene expression internal control check as detected by a 435 amplicon in all cell-lines. Lane 1 WS, lane $2 \mathrm{TK}^{+}{ }^{+}$, lane $3 \mathrm{TK} 1^{-}$, lane $4 \mathrm{GM} 38$ and lane 5 PCR water control. M is a $100 \mathrm{bp}$ ladder. (C) HTERT gene expression detected by a $200 \mathrm{bp}$ amplicon. HTERT gene expression was found in the WS cell-line, TK1 ${ }^{+}$and
TK1- cells, but not GM38. Lane 1 WS, lane 2TK1+, lane 3 Raji TK1- , lane 4 GM38 lane 5 -RTPCR control (-RT) WS, lane 6 -RT TK1+ , lane 7 -RT TK1-', lane 8 -RT GM38, lane 9 PCR water control. M is a $100 \mathrm{bp}$ ladder (D) TP53 gene expression as detected by a $1220 \mathrm{bp}$ band present in all cells. Lane 1 $\mathrm{GM} 38$, lane $2 \mathrm{GM} 38$-RT, lane 3 Raji TK1 ${ }^{+}$, lane 4 Raji TK1 ${ }^{+}-\mathrm{RT}$, lane 5 Raji TK1 ${ }^{-}$, lane 6 Raji TK1 ${ }^{-}$-RT, lane 7 PCR water control. M is a 100 bp ladder.
hTERT spots compared to tail bulk DNA. Figure 4D demonstrates how reduction of \% comet tail DNA damage occurs at more similar rates for both bulk DNA and the TP53 and hTERT gene regions in the $\mathrm{TK} 1^{-}$cell-line. The pattern of repair observed in each gene region would suggest that preferential repair is occurring in the TP53 and hTERT domains of Raji TK1 ${ }^{+}$but not in $\mathrm{TK}^{-}$cells.

\section{EFFECT OF THYMIDINE FREE CULTURE ON PREFERENTIAL REPAIR CAPABILITIES OF RAJI TK1 ${ }^{+}$CELLS}

The growth of $\mathrm{TK}^{+}$cells in thymidine free media (Raji $\mathrm{TK}^{+}$ Thy $^{-}$) had no impact on the proficiency of single strand repair of bulk DNA in Raji TK1 ${ }^{+}$cells (Figure 5A) or gene region-specific repair of TP53 (Figure 5B) or hTERT (Figure 5C). Figure 5B shows TP53 repair in Raji $\mathrm{TK}^{+}{ }^{+} \mathrm{Thy}^{+}$and Raji $\mathrm{TK}^{+}{ }^{+} \mathrm{Thy}^{-}$ cells. Statistical analysis found no significant difference in the $\%$ of TP53 tail signals between $\mathrm{TK}^{+}{ }^{+} \mathrm{Thy}^{+}$and Raji $\mathrm{TK}^{+}{ }^{+} \mathrm{Thy}^{-}$ cells $(p>0.05)$. Statistical analysis likewise found no significant difference in the \% hTERT tail signals at any given time points. These experiments show that culturing of $\mathrm{TK}^{+}{ }^{+}$cells in thymidine free media has no effect on the level of preferential repair.

\section{DISCUSSION}

The misrepair of DNA damage can result in tumorigenesis through mutational activation of proto-oncogenes and inactivation of tumor suppressor genes, causing a variety of human cancer syndromes. Although TK1 deficiency is known to cause a clear increase in DNA damage sensitivity and mutagenicity, and the likelihood of increased carcinogenesis, the DNA repair process on which the salvage enzyme exerts its protective effects remains to be elucidated. While our results in human cells show that TK1 deficiency can reduce the rate of bulk DNA repair, the most prominent finding is the clear role for TK1 in repair of damage occurring in specific gene regions. It is of further interest to monitor DNA repair processes 

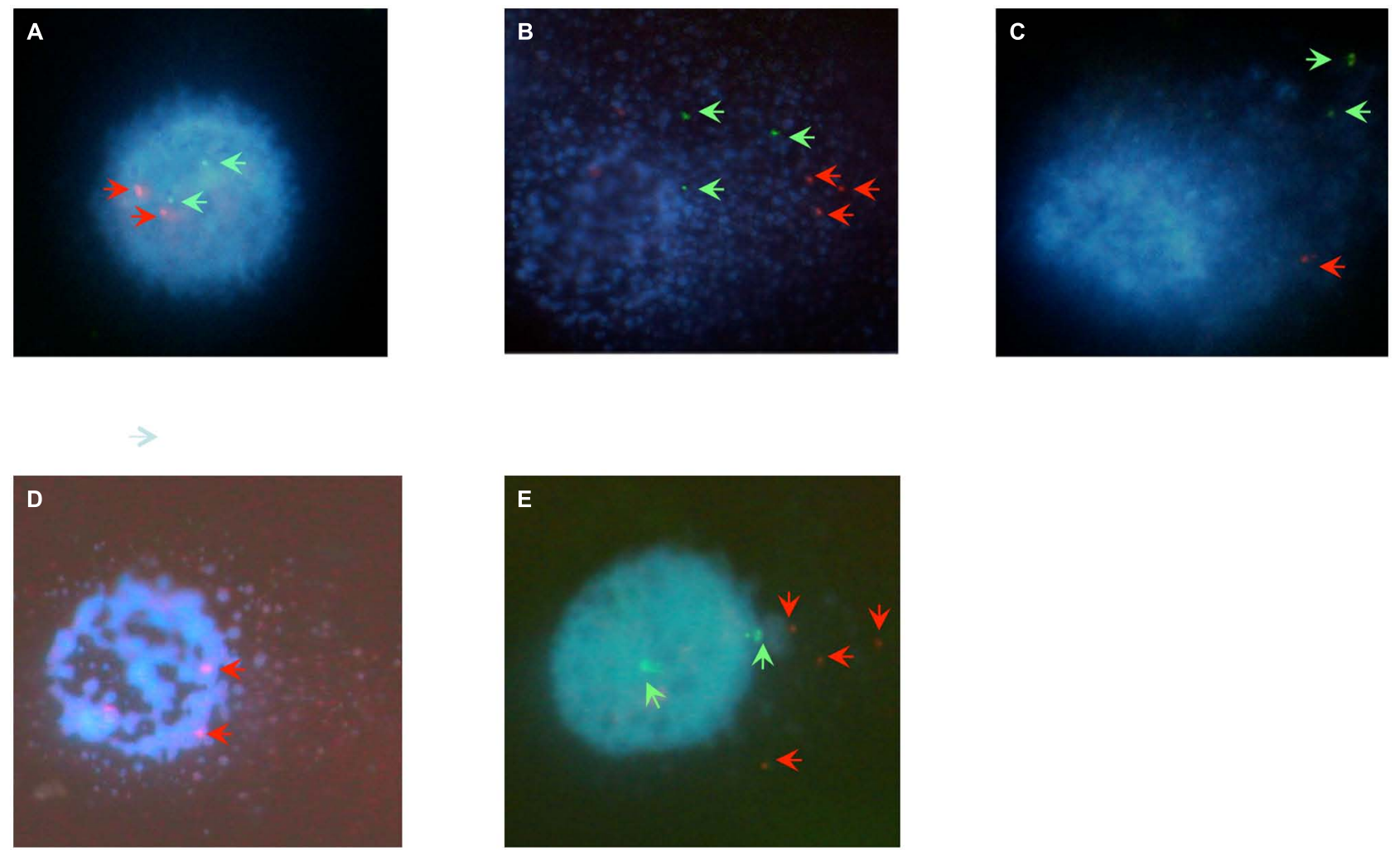

FIGURE 3 | Digital imaging of comet-FISH cells. The position of TP53 and hTERT hybridization spots in the comet head or tail specifies whether it lies in, or close to, a region of intact or damaged DNA. Observations for imaging were made at a final magnification of $\times 600$ (Nikon $\times 60$ Fluor lens). (A) An untreated Raji cells displays minimal DNA damage as evidenced by the intact comet head and minimal comet tail. Two TP53 (red arrows) and two hTERT (green arrows) hybridization spots are visible in the intact comet head.

(B,C) Immediately following 5Gy $\gamma$-irradaition a large comet tail is visualized, indicating a large amount of overall DNA damage, with red TP53 and green
hTERT hybridization spots in the comet tail indicating that radiation-induced strand breaks have occurred within or close to the vivinity of both genes of (B) $\mathrm{TK}^{+}$and (C) $\mathrm{TK}^{-}$cells. (D). At 15 min of repair the $\mathrm{TK}^{+}$cells have repaired most gene specific damage as depicted here for the TP53 gene region, as evidenced here by the FISH spots being located in the head. (E) Raji TKcells at 60 min post-irradiation typically feature TP53 and/or HTERT FISH spots located in the comet-head as gene repair has begun to recover. However, FISH tail spots still remain in higher numbers than $\mathrm{TK}^{+}$, this picture showing an example of damage remaining in the TP53 locci of $\mathrm{TK}^{-}$cells at $60 \mathrm{~min}$. in actual cancer cell-lines such as Burkitt's lymphoma-derived Raji, as a full appreciation of the mechanisms that govern DNA repair efficiency in such cells could help lead to the development of novel chemotherapeutic agents, and also help predict patient response to radiotherapy (McKenna et al., 2008).

Table 1 | Data generated by the comet-FISH assay for both Raji $\mathrm{TK}^{+}$and $\mathrm{TK}^{-}$cells at $0,15,30$, and 60 min following a dose of $5 \mathrm{~Gy} \gamma$-irradiation.

\begin{tabular}{|c|c|c|c|c|c|}
\hline Cell-line & Percentage (\%) & 0 & 15 & 30 & 60 \\
\hline \multirow[t]{3}{*}{ Raji TK+ } & DNA in the comet tail & $31.76 \pm 1.25$ & $18.36 \pm 1.24$ & $12.82 \pm 1.41$ & $8.05 \pm 0.74$ \\
\hline & TP53 comet tail signals & $70.05 \pm 2.20$ & $22.31 \pm 2.61$ & $18.22 \pm 3.03$ & $7.53 \pm 2.19$ \\
\hline & hTERT comet tail signals & $77.50 \pm 1.89$ & $29.77 \pm 3.12$ & $15.03 \pm 2.37$ & $6.82 \pm 1.88$ \\
\hline & TP53 comet tail signals & $62.28 \pm 2.45$ & $57.49 \pm 2.41$ & $37.63 \pm 3.46$ & $17.12 \pm 2.36$ \\
\hline & hTERT comet tail signals & $74.05 \pm 3.16$ & $59.59 \pm 3.02$ & $39.87 \pm 3.80$ & $29.82 \pm 3.19$ \\
\hline
\end{tabular}

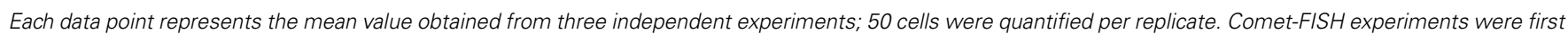
evaluated by quantifying the number of TP53 and hTERT hybridization spots located in the comet head or tail of TK $1^{+}$and TK $1^{-}$at each repair incubation time. 


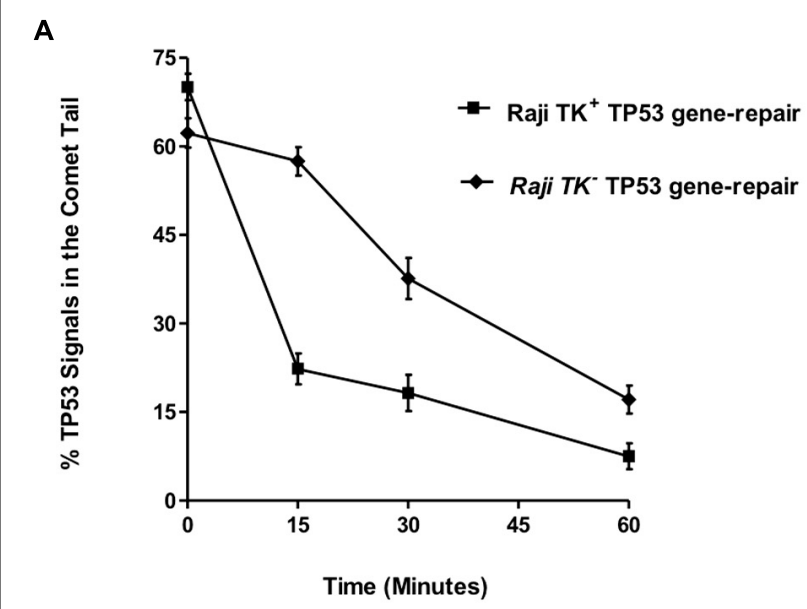

C

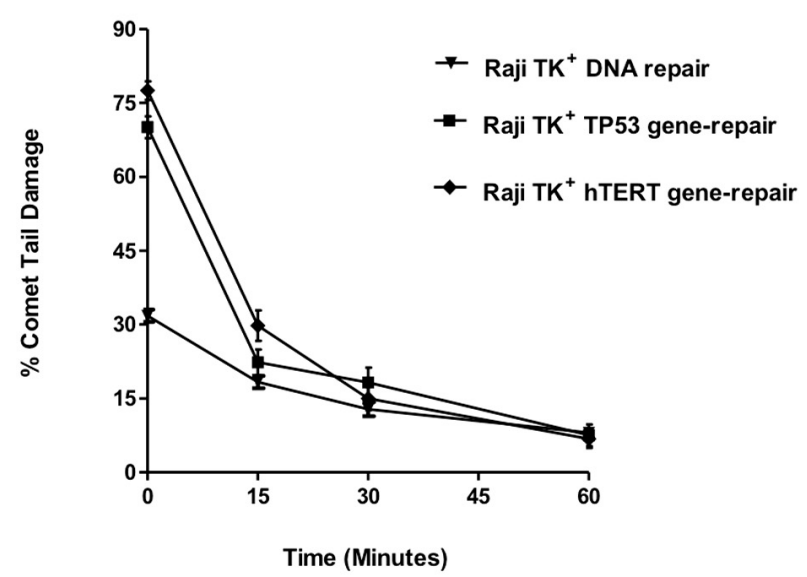

FIGURE 4 |TP53 and hTERT gene-repair in TK1 ${ }^{-}$and TK1 $^{+}$cells and comparison with the overall genome. (A) shows the \% TP53 tail signals and (B) the \% hTERT tail signals over the repair time period after 5 Gy-irradiation. (C,D) compares DNA repair between the overall genome and specific gene-regions. These findings demonstrate
B

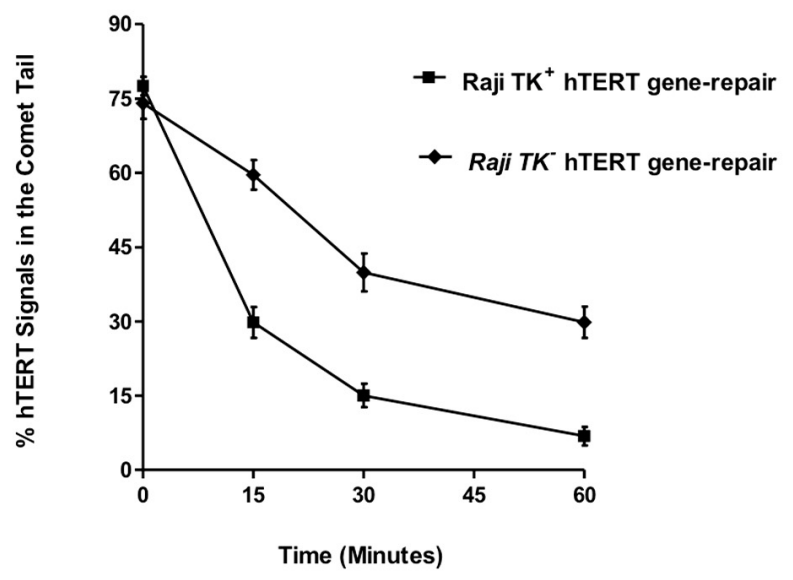

D

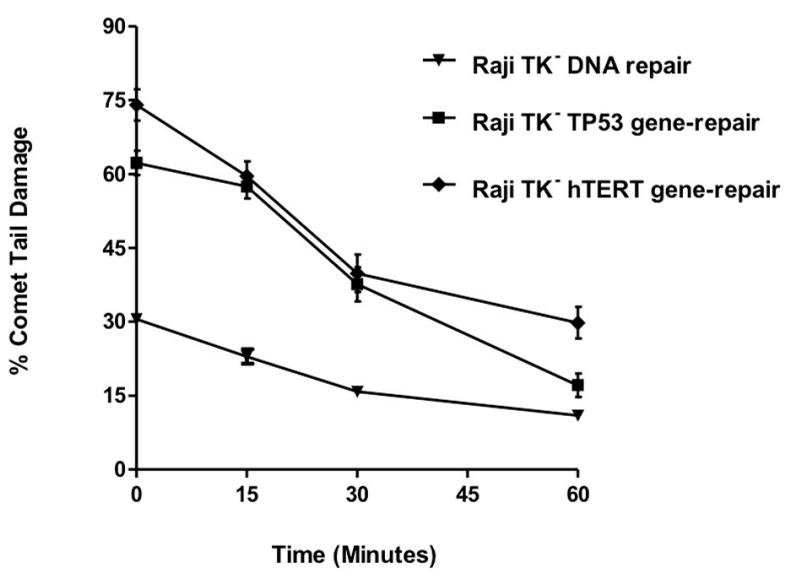

that preferential repair is occurring in the TP53 and hTERT domains of Raji $\mathrm{TK}_{1}{ }^{+}$but not in $\mathrm{TK} 1^{-}$cells. In each graph, fifty cells were analyzed at each time-point for each experimental replicate. Each data point represents the mean \pm SEM of three independent replicate experiments.
We confirmed that TP53 and hTERT are substrates for preferential repair of gene sequences repair in Raji cells - intrinsically probable, since TP53 is transcribed throughout the cell cycle (Liu and Chen, 2006) and further induced by DNA-damaging agents, while the hTERT gene is upregulated in malignant cells such as Raji (Ducrest et al., 2002). RTPCR analysis found that both $\mathrm{TK}^{+}$and $\mathrm{TK}^{-}{ }^{-}$clones actively expressed the hTERT and TP53 genes. Also, since the correct function of the TP53 gene product is a major factor in mediating DNA repair processes (reviewed by McKay et al., 1999 ) it is possible that disparity in DNA repair between $\mathrm{TK} 1^{+}$ and $\mathrm{TK}^{-}$cells could arise if there were different TP53 mutations in either cell-line. Sequencing results for both $\mathrm{TK}^{+}$and TK1 ${ }^{-}$clones confirmed that the $\mathrm{TK}^{+}$and $\mathrm{TK}^{-}$clones have the same TP53 mutations and should therefore have the same tumor suppressor protein function during DNA repair.

The Comet-FISH data show that although TK deficiency does not prevent the repair of strand breaks in bulk DNA, it is slower in the TK1 deficient cell-line. The slight deceleration in bulk DNA repair in $\mathrm{TK}^{-}$is likely a reflection of the markedly reduced repair occurring in damaged regions containing transcribed genes. Our data shows that Raji TK1 ${ }^{-}$cells display poor initial repair of regions containing transcribed genes (as evidenced by a slower reduction of TP53 and hTERT tail hybridization signals). The rapid TP53 gene region repair demonstrated in $\mathrm{TK}^{+}$cells is also consistent with other studies of repair in this gene (McKenna et al., 2003; Horvathova et al., 2004). These results clearly demonstrate that TK1 is necessary for the rapid repair of both the TP53 and hTERT gene region.

One possibility to explain the difference in preferential repair between $\mathrm{TK}^{+}{ }^{+}$and $\mathrm{TK}^{-}$clones is that $\mathrm{TK} 1$ provides a dTTP pool that facilitates the rapid repair of damaged genes. Raji $\mathrm{TK} 1^{+}$cells were therefore cultured in thymidine free media to deprive TK of its substrate, and damage induced gene 


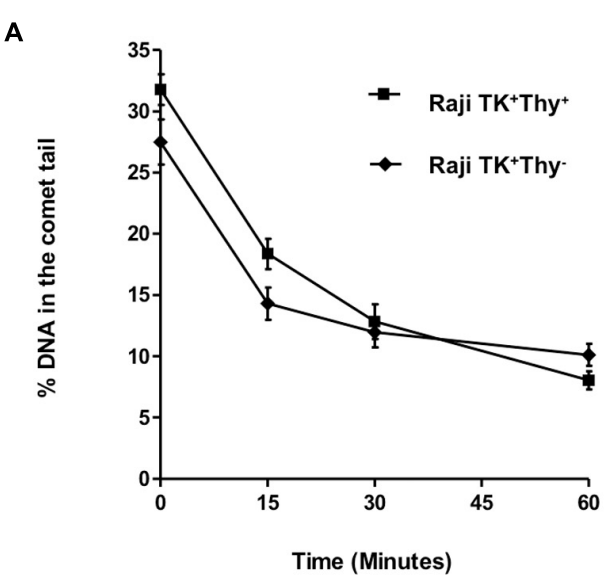

B

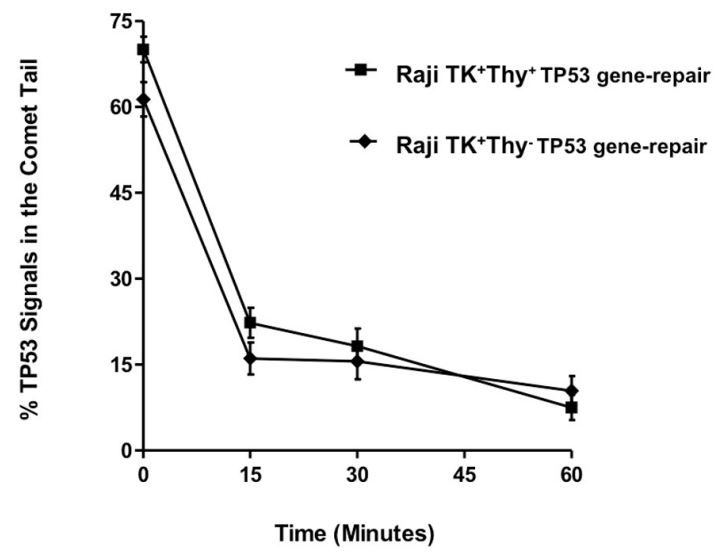

FIGURE 5 | Effect of thymidine salvage depletion in Raji TK1 ${ }^{+}$cells. (A) depicts the repair of bulk DNA, while graphs $(\mathbf{B}, \mathbf{C})$ show the \% TP53 and hTERT tail signals over the repair time period after 5 Gy-irradiation. The rapid gene repair observed clearly demonstrates that culturing of TK1 ${ }^{+}$cells in
C

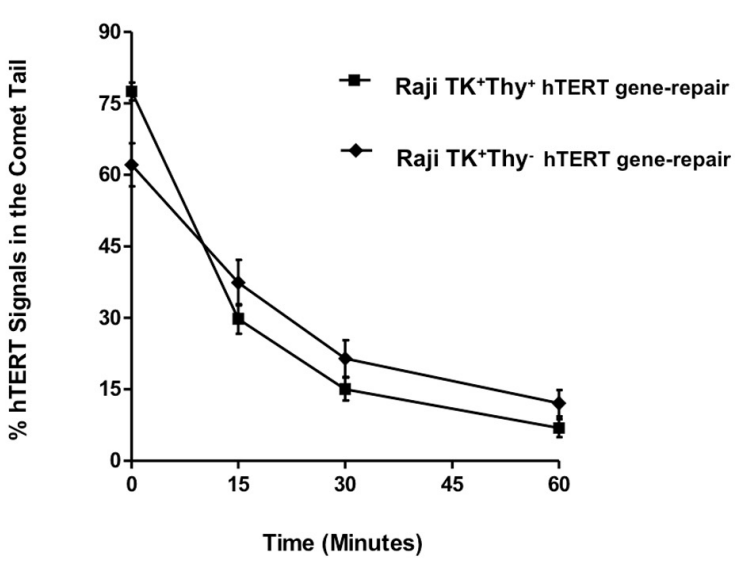

thymidine free media has no effect on the level of preferential repair. Fifty cells were analyzed at each time-point for each experimental replicate. Each data point represents the mean \pm SEM of three independent replicate experiments. region specific and bulk DNA repair were assessed. The results showed that the preferential repair capabilities of $\mathrm{TK}^{+}$cells were unaffected: therefore TK1 does not exert its effects through deoxyribonucleotide pools, otherwise repair of TK1 $1^{+}$cells would have been rendered similar to that of repair deficient $\mathrm{TK}^{-}$ cells.

We have thus demonstrated that TK1 is a novel factor regulating preferential, gene-specific repair, operating not through its enzymic role but by some other mechanism: possibly activation of another protein involved in the repair process. There is no current evidence for direct interaction of TK1 protein with any known component of the single-strand break repair pathway. If one were to speculate, one might propose as a possible candidate for direct or indirect dependence on TK protein the DNA 3'phosphatase, in some circumstances a rate-limiting factor in single-strand break repair (Breslin and Caldecott, 2009). We note that defects in TK are well established as being mutagenic, and hence they are presumably also carcinogenic.

\section{ACKNOWLEDGMENTS}

We thank Dr. Bernadette Doherty, University of Ulster, for technical support with the Comet FISH assay. This work was supported by a NI DEL studentship to Katherine A. McAllister.

\section{REFERENCES}

al-Nabulsi, I., Takamiya, Y., Voloshin, Y., Dritschilo, A., Martuza, R. L., and Jorgensen, T. J. (1994). Expression of thymidine kinase is essential to low dose radiation resistance of rat glioma cells. Cancer Res. 54, 5614-5617.

Best, C. J., McKelvey-Martin, V. J., and McKenna, P. G. (1994). Effects of thymidine kinase and methyltransferase deficiency on mutagenesis in a human lymphoblastoid cell line. Mutat. Res. 309, 235-242. doi: 10.1016/0027-5107(94) 90097-3

Boothman, D. A., Davis, T. W., and Sahijdak, W. M. (1994). Enhanced expression of thymidine kinase in human cells following ionizing radiation. Int. J. Radiat. Oncol. Biol. Phys. 30, 391-398. doi: 10.1016/0360-3016(94) 90019-1

Breslin, C., and Caldecott, K. W. (2009). DNA $3^{\prime}$-phosphatase activity is critical for rapid global rates of single-strand break repair following oxidative stress. Mol. Cell Biol. 29, 4653-4662. doi: 10.1128/MCB.00677-09

Castro Kreder, N. C., van Bree, C., Peters, G. L., Loves, W. J., and Haveman, J. (2002). Enhanced levels of deoxycytidine kinase and thymidine kinase 1 and 2 
after pulsed low dose rate irradiation as an adaptive response to radiation. Oncol. Rep. 9, 141-144.

Chen, Y. L., Eriksson, S., and Chang, Z. F. (2010). The regulation and functional contribution of thymidine kinase 1 in repair of DNA damage. J. Biol. Chem. 16, 27327-27335. doi: 10.1074/jbc.M110.137042

Ducrest, A. L., Szutorisz, H., Lingner, J., and Nabholz, M. (2002). Regulation of the human telomerase reverse transcriptase gene. Oncogene 21, 541-552. doi 10.1038/sj.onc. 1205081

Dobrovolsky, V. N., Bucci, T., Heflich, R. H., Desjardins, J., and Richardson, F. C. (2003). Mice deficient for cytosolic thymidine kinase gene develop fatal kidney disease. Mol. Genet. Metab. 78, 1-10. doi: 10.1016/S1096-7192(02) 00224-X

Frankenberg-Schwager, M. (1989). Review of repair kinetics for DNA damage induced in eukaryotic cells in vitro by ionizing radiation. Radiother. Oncol. 14 307-320. doi: 10.1016/0167-8140(89)90143-6

Glei, M., Schaeferhenrich, A., Claussen, U., Kuechler, A., Liehr, T., Weise, A., et al (2007). Comet fluorescence in situ hybridization analysis for oxidative stressinduced DNA damage in colon cancer relevant genes. Toxicol. Sci. 96, 279-284. doi: 10.1093/toxsci/kfl197

Hampar, B., Derge, J. G., Marto, L. M., and Walker, J. L. (1971). Synthesis of Epstein-Barr virus after activation of the viral genome in a "virusnegative" human lymphoblastoid cell (Raji) made resistant to 5-bromodeoxyuridine. Proc. Natl. Acad. Sci. U.S.A. 69, 78-82. doi: 10.1073/pnas. 69.1 .78

Haveman, J., Sigmond, J., van Bree, C., Franken, N. A., Koedooder, C., and Peters, G. J. (2006). Time course of enhanced activity of deoxycytidine kinase and thymidine kinase 1 and 2 in cultured human squamous lung carcinoma cells, SW-1573, induced by gamma-irradiation. Oncol. Rep. 16, 901-905.

Hiyama, E., and Hiyama, K. (2003). Telomerase as tumour marker. Cancer Lett. 194, 221-223. doi: 10.1016/S0304-3835(02)00709-7

Horvathova, E., Dusinska, M., Shaposhnikov, S., and Collins, A. R. (2004). DNA damage and repair measured in different genomic regions using the comet assay with fluorescent in situ hybridization. Mutagenesis 19, 269-276. doi 10.1093/mutage/geh030

Hu, C. M., and Chang, Z. F. (2008). Synthetic lethality by lentiviral short hairpin RNA silencing of thymidylate kinase and doxorubicin in colon cancer cells regardless of the p53 status. Cancer Res. 69, 2831-2840. doi: 10.1158/00085472.CAN-07-3069

Hyland, P., Keegan, A. L., Curran, M. D., Middleton, D., McKenna, P. G., and Barnett, Y. A. (2000). Effect of a dCTP, dTTP pool imbalance on DNA replication fidelity in Friend murine erythroleukemia cells. Environ. Mol. Mutagen. 36, 87-96. doi: 10.1002/1098-2280(2000)36:2<87::AID-EM2>3.0. $\mathrm{CO} ; 2-\mathrm{A}$

Karran, P., Stephenson, C., Cairns-Smith, S., and Macpherson, P. (1990). Regulation of O6-methylguanine-DNA methyltransferase expression in the Burkitt's lymphoma cell line Raji. Mutat. Res. 233, 23-30. doi: 10.1016/0027-5107(90) 90147-V

Kubota, M., Wakazono, Y., and Furusho, K. (1998) Increased cell killing and mutagenecity by DNA alkylating agents in cells with decreased TTP pools. Adv. Exp. Med. Biol. 431, 611-616. doi: 10.1007/978-1-4615-5381-6_118

Liu, G., and Chen, X. (2006). Regulation of the p53 transcriptional activity. J. Cell Biochem. 97, 448-458. doi: 10.1002/jcb.20700

Matlashewski, G., Lamb, P., Pim, D., Peacock, J., Crawford, L., and Benchimol, S. (1984). Isolation and characterization of a human p53 cDNA clone: expression of the human p53 gene. EMBO J. 3, 3257-3262.

McKay, B. C., Ljungman, M., and Rainbow, A. J. (1999). Potential roles for p53 in nucleotide excision repair. Carcinogenesis 20, 1389-1396. doi: $10.1093 /$ carcin/20.8.1389

McKelvey-Martin, V. J., Ho, E. T., McKeown, S. R., Johnston, S. R., McCarthy, P. J., Rajab, N. F., et al. (1998). Emerging applications of the single cell gel electrophoresis (Comet) assay. I. Management of invasive transitional cell human bladder carcinoma. II. Fluorescent in situ hybridization Comets for the identification of damaged and repaired DNA sequences in individual cells. Mutagenesis 13, 1-8. doi: 10.1093/mutage/13.1.1

McKenna, D. J., Doherty, B. A., Downes, C. S., McKeown, S. R., and McKelveyMartin, V. J. (2012). Use of the Comet-FISH assay to compare DNA damage and repair in p53 and hTERT genes following ionizing radiation. PLoS ONE 7:1371. doi: 10.1371/journal.pone.0049364
McKenna, P. G., and Hickey, I. (1981). UV-sensitivity in thymidine kinase-deficient mouse erythroleukaemia cells. Cell Biol. Int. Rep. 5, 555-561. doi: 10.1016/S03091651(81)80006-9

McKenna, P. G., and McKelvey, V. J. (1986). Abilities of wild-type and thymidine kinase-deficient Friend mouse erythroleukemia cells to undergo unscheduled DNA synthesis following mutagen treatment. Somat. Cell Mol. Genet. 12, 325332. doi: $10.1007 / \mathrm{BF} 01570726$

McKenna, P. G., McKelvey, V. J., and Frew, T. L. (1988). Sensitivity to cell killing and the induction of cytogenetic damage following gamma irradiation in wild-type and thymidine kinase-deficient Friend mouse erythroleukaemia cells. Mutat. Res. 200, 231-242. doi: 10.1016/0027-5107(88) 90087-5

McKenna, D. J., Rajab, N. J., McKeown, S. R., McKerr, G., and McKelveyMartin, V. J. (2003). Use of the Comet-FISH assay to demonstrate repair of the TP53 gene region in two human bladder carcinoma cell lines. Radiat. Res. 159, 49-56. doi: 10.1667/0033-7587(2003)159[0049:UOTCFA]2. $0 . \mathrm{CO} ; 2$

McKenna, D. J., McKeown, S. R., and McKelvey-Martin, V. J. (2008). Potential use of the Comet assay in the clinical management of cancer. Mutagenesis 23, 183-190. doi: 10.1093/mutage/gem054

McKenna, P. G., and Yasseen, A. A. (1982). Increased sensitivity to cell killing and mutagenesis by chemical mutagens in thymidine kinase-deficient sub clones of a Friend murine leukaemia cell line. Genet. Res. 40, 207-212 doi: 10.1017/S0016672300019078

McKenna, P. G., Yasseen, A. A., and McKelvey, V. J. (1985). Evidence for indirect involvement of thymidine kinase in excision repair processes in mouse cell lines. Somat. Cell Mol. Genet. 11, 239-246. doi: 10.1007/BF01534680

Santos, S. J., Singh, N. P., and Natarajan, A. T. (1997). Fluorescence in situ hybridization with comets. Exp. Cell. Res. 232, 407-411. doi: 10.1006/excr.1997. 3555

Sarasin, A., and Stary, A. (2007). New insights for understanding the transcription-coupled repair pathway. DNA Repair. 6, 265-269. doi: 10.1016/j.dnarep.2006.12.001

Segura-Pena, D., Lutz, S., Monnerjahn, C., Konrad. M., and Lavie, A. (2007). Binding of ATP to TK1-like enzymes is associated with a conformational change in the quaternary structure. J. Mol. Biol. 25, 129-141. doi: 10.1016/j.jmb.2007. 02.104

Wakazono, Y., Kubota, M., Furusho, K., Liu, L., and Gerson, S. L. (1996). Thymidine kinase deficient cells with decreased TTP pools are hypersensitive to DNA alkylating agents. Mutat. Res. 362, 119-125. doi: 10.1016/0921-8777(95) 00042-9

Wei, S., Ageron-Blanc, A., Petrididis, F., Beaumatin, J., Bonnet, S., and Luccioni, C. (1999). Radiation-induced changes in nucleotide metabolism of two colon cancer cell lines with different radiosensitivities. Int. J. Radiat. Biol. 75, 1005-1013. doi: 10.1080/095530099139764

Wilkinson, Y. A., and McKenna, P. G. (1989). The effects of thymidine on deoxyribonucleotide pool levels, cytotoxicity and mutation induction in Friend mouse erythroleukaemia cells. Leuk. Res. 13, 615-620. doi: 10.1016/01452126(89)90130-6

Conflict of Interest Statement: The authors declare that the research was conducted in the absence of any commercial or financial relationships that could be construed as a potential conflict of interest.

Received: 30 April 2014; paper pending published: 22 May 2014; accepted: 30 June 2014; published online: 08 August 2014.

Citation: McAllister KA, Yasseen AA, McKerr G, Downes CS and McKelvey-Martin $V J$ (2014) FISH comets show that the salvage enzyme TK1 contributes to gene-specific DNA repair. Front. Genet. 5:233. doi: 10.3389/fgene.2014.00233

This article was submitted to Genomic Assay Technology, a section of the journal Frontiers in Genetics.

Copyright (c) 2014 McAllister, Yasseen, McKerr, Downes and McKelvey-Martin. This is an open-access article distributed under the terms of the Creative Commons Attribution License (CC BY). The use, distribution or reproduction in other forums is permitted, provided the original author(s) or licensor are credited and that the original publication in this journal is cited, in accordance with accepted academic practice. No use, distribution or reproduction is permitted which does not comply with these terms. 